\title{
Release of pig leukocytes and reduced human NK cell recruitment during ex vivo perfusion of HLA-E/human CD46 double-transgenic pig limbs with human blood
}

Gisella Puga Yung ${ }^{1}$, Anjan K. Bongoni ${ }^{2}$, Amandine Pradier ${ }^{1}$, Natacha Madelon ${ }^{1}$, Maria Papaserafeim ${ }^{1}$, Riccardo Sfriso ${ }^{2}$, David L. Ayares ${ }^{3}$, Eckhard Wolf ${ }^{4}$, Nikolai Klymiuk ${ }^{4}$, Andrea Bähr ${ }^{4}$, Mihai A. Constantinescu ${ }^{5}$, Esther Voegelin ${ }^{5}$, David Kiermeir ${ }^{5}$, Hansjörg Jenni ${ }^{6}$, Robert Rieben ${ }^{2}$, Jörg D.

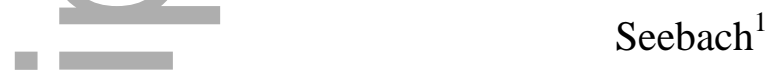

Running title: Ex vivo xenoperfusion of pig forelimbs

${ }^{1}$ Division of Immunology and Allergology, University Hospital and Medical Faculty, Geneva, Switzerland

${ }^{2}$ Department of Clinical Research, University of Bern, Bern, Switzerland

${ }^{3}$ Revivicor Inc., Blacksburg, VA, USA

${ }^{4}$ Institute of Molecular Animal Breeding and Biotechnology, Ludwig-Maximilian University, Munich, Germany

${ }^{5}$ Clinic of Plastic and Hand Surgery, University Hospital, Bern, Switzerland

${ }^{6}$ Clinic of Cardiovascular Surgery, University Hospital, Bern, Switzerland

Correspondence:

Jörg D. Seebach, MD

University Hospital Geneva

Division of Clinical Immunology and Allergy

Rue Gabrielle Perret Gentil 4

CH-1211 Geneva 14

This is the author manuscript accepted for publication and has undergone full peer review but has not been through the copyediting, typesetting, pagination and proofreading process, which may lead to differences between this version and the Version of Record. Please cite this article as doi:

$\underline{10.1111 / \text { xen. } 12357}$

This article is protected by copyright. All rights reserved 
Switzerland

Phone: +41 223729372

Fax: +41223729418

Email: joerg.seebach@hcuge.ch

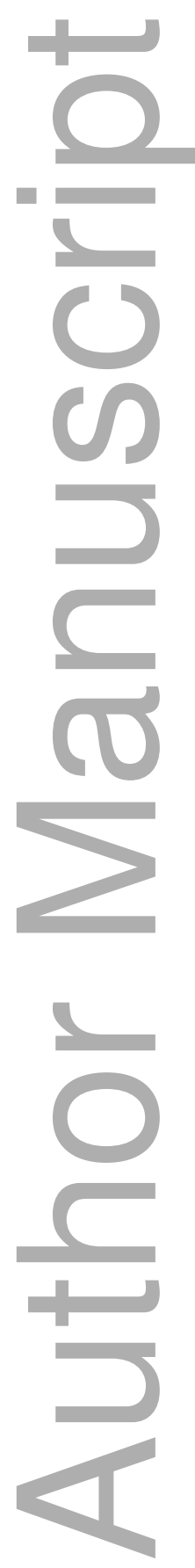


MR. RICCARDO SFRISO (Orcid ID : 0000-0002-3406-0736)

PROF. ROBERT RIEBEN (Orcid ID : 0000-0003-4179-8891)

DR. JÖRG DIETER SEEBACH (Orcid ID : 0000-0001-5748-4577)

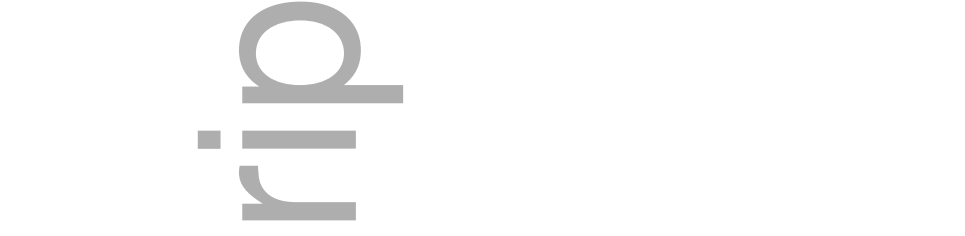

Article type :Original Article

\section{ABSTRACT}

Background: In pig-to-human xenotransplantation interactions between human natural killer (NK) cells and porcine endothelial cells (pEC) are characterized by recruitment and cytotoxicity. Protection from xenogeneic NK cytotoxicity can be achieved in vitro by the expression of the non-classical human leukocyte antigen-E (HLA-E) on pEC. Thus, the aim of the present study was to analyze NK cell responses to vascularized xenografts by using an ex vivo perfusion system of pig limbs with human blood.

Methods: Six pig forelimbs per group, respectively, stemming from either wild-type (wt) or HLAE/hCD46 double transgenic (tg) animals, were perfused ex vivo with heparinized human blood for $12 \mathrm{~h}$. Blood samples were collected at defined time intervals, cell numbers counted and peripheral blood mononuclear cells analyzed for phenotype by flow cytometry. Muscle biopsies were analyzed for NK cell infiltration. In vitro NK cytotoxicity assays were performed using pEC derived from wt and tg animals as target cells.

Results: Ex vivo, a strong reduction of circulating human CD45 leukocytes was observed after 60 min of xenoperfusion in both wt and tg limb groups. NK cell numbers dropped significantly. Within the first $10 \mathrm{~min}$, the decrease of NK cells was more significant in the wt limb perfusions as compared to tg limbs. Immunohistology of biopsies taken after $12 \mathrm{~h}$ showed less NK cell tissue infiltration in the $\mathrm{tg}$ limbs. In vitro, NK cytotoxicity against hCD46 single tg $\mathrm{pEC}$ and wt $\mathrm{pEC}$ was similar, while lysis of 
double tg HLA-E/hCD46 pEC was significantly reduced. Finally, circulating cells of pig origin were observed during the ex vivo xenoperfusions. These cells expressed phenotypes mainly of monocytes, B and T lymphocytes, NK cells, as well as some activated endothelial cells.

Conclusions: Ex vivo perfusion of pig forelimbs using whole human blood represents a powerful tool to study humoral and early cell-mediated rejection mechanisms of vascularized pig-to-human xenotransplantation, although there are several limitations of the model. Here we show that (1) transgenic expression of HLA-E/hCD46 in pig limbs provides partial protection from human NK cellmediated xeno responses, and (2) the emergence of a pig cell population during xenoperfusions with implications for the immunogenicity of xenografts.

KEYWORDS: Xenoperfusion, limb perfusion, NK cells, HLA-E/hCD46, transgenic pigs, release of pig cells.

ABBREVIATIONS: BL, base-line; FSC, forward-scatter; hCD45, human CD45 positive cells, hCD45 ${ }^{\text {neg }}$, human CD45 negative cells; HLA, human leukocyte antigen; mAb, monoclonal antibody; MHC, major histocompatibility complex; NK, natural killer; pCD45, pig CD45 positive cells; pCD45 ${ }^{\text {neg }}$, pig CD45 negative cells; pEC, porcine endothelial cells; PBS, phosphate buffered saline; PBMC, peripheral blood mononuclear cells; SLA, swine lymphocyte antigen; SSC, side-scatter; tg, transgenic; WBC, white blood cells; wt, wild-type.

\section{INTRODUCTION}

The use of porcine organs or cells to overcome the current shortage in transplantation medicine faces several challenges, including innate and adaptive immune responses. From the clinical point of view, adaptive responses might be controlled by immunosuppressive drugs currently used in allotransplantation; however, therapeutic approaches to control innate immunity remain to be developed. Cellular innate immunity causing early endothelial damage following xenotransplantation of vascularized organs is mediated by granulocytes, monocytes, and NK cells [1-4]. The activity of human NK cells is tightly regulated by a balance between activating and inhibiting NK cell receptors, the latter predominantly recognizing self MHC class I molecules [5]. In the pig-to-human setting, pig MHC class I, i.e. swine leukocyte antigen I (SLA-I), is poorly recognized by human inhibitory NK cell This article is protected by copyright. All rights reserved 
receptors [6]. Indeed, overexpression of SLA-I on porcine endothelial cells (pEC) by stimulation with tumor necrosis factor reduced but did not fully abrogate human anti-pig NK cytotoxicity [7]. As a strategy to control xenogeneic human anti-pig NK cytotoxicity, we and others have previously shown that transgenic expression of various human leukocyte antigen (HLA) class-I molecules including HLA-A2, -B27, - $\mathrm{Cw} 3,-\mathrm{Cw} 4$, and HLA-G in pEC provides partial protection against NK cytotoxicity and reduces NK cell recruitment [8-15]. In contrast to the classical, highly polymorphic HLA-A/B/C alleles, HLA-E alleles are restricted to only two functional variants recognized by the ubiquitous inhibitory NK receptor CD94/NKG2A [16-18]. Consequently, transgenic expression of HLA-E in pig xenografts might inhibit a large majority of NK cells in human recipients, and avoids the introduction of potentially allogeneic HLA molecules. Thus, we and others have used different HLA-E constructs to transfect porcine endothelial cells, including a trimer consisting of mature human $\beta 2 \mathrm{~m}$; a canonical HLA-E binding peptide VMAPRTLIL; and mature HLA-E ${ }^{\mathrm{R}}$ heavy chain, E*0103 [19-23]. Subsequently, HLA-E and human $\beta 2 \mathrm{~m}$ contained in two separated vectors were used to generate HLA$\mathrm{E} / \beta 2 \mathrm{~m}$ transgenic pigs as a strategy to regulate human anti-pig NK cell responses [24]. Whereas in vitro NK cytotoxicity against HLA-E expressing pEC was reduced, this strategy is only now being tested under more physiological conditions such as ex vivo perfusion systems.

Ex vivo perfusion models have been used in xenotransplantation for many years to test early xenograft events and more recently to evaluate the potential of genetic modifications in pigs. Preferential recruitment of human NK cells, to rat hearts perfused with human peripheral blood lymphocytes, was reported in a seminal paper by Inverardi et al. in 1992 [25]. A predominance of perivascular xenograft infiltration by NK cells was also demonstrated by Khalfoun et al. during pig kidney xenoperfusions with human peripheral blood lymphocytes [26], and by Ramos et al. in a short report [27]. Using a pig lung xenoperfusion model Laird et al reported recently that transgenic expression of HLA-E limited endothelial damage by preventing NK-cell activation and cytotoxicity resulting in improved pig lung survival and function [28]. This finding was corroborated in the Munich heart model showing reduced tissue infiltration by NK cells in HLA-E transgenic pig hearts perfused with human blood, as recently reported in abstract form [28-31].

During the past years our collaborative group has established a novel model of ex vivo xenoperfusion with human blood using porcine forelimbs of genetically modified pigs [32]. In the current work, a combined strategy to reduce humoral and cellular innate xenoresponses by overexpression of HLA-E and hCD46, respectively, was used to study interactions between human NK cells and the porcine 
vascular system. While HLA-E expression, tissue damage and the effects on complement activation and coagulation all have been reported in detail elsewhere [33-36], we describe here the effect of combined HLA-E/hCD46 expression on NK cell recruitment and tissue infiltration. Additionally, the release into the circulating blood of an important population of pig cells was observed during these xenoperfusions and further characterized.

\section{MATERIAL AND METHODS}

Animals and pig limb perfusion model. Ex vivo perfusion was performed as described in detail elsewhere [35]. Six HLA-E/hCD46 double transgenic (tg) [24] and six wild-type (wt) pig forelimbs were perfused with heparinized whole human blood (xenoperfusion). Animal care was performed according to the Swiss National Guidelines and the Guide for the Care and Use of Laboratory Animals (NIH Publication No. 85-23, revised 1996). The local animal experimentation committee of the Canton Bern approved this study (permission \# BE45/11). Serial blood samples of $10 \mathrm{ml}$ were collected from the perfusion system at predefined intervals, starting at base-line (BL) before the blood was added to the perfusion system, and after 10,60, 180 and 720 min of perfusion. Muscle biopsies were obtained for analysis of cellular tissue infiltration before perfusion and at the end-point (720 min).

White blood cell counts. Complete hemograms including white blood cell (WBC) counts were performed on each blood sample by using an analyzer (Sysmex Europe GmbH, Norderstedt, Germany).

Human and pig cell isolation from perfused blood. Peripheral blood mononuclear cells (PBMC) were isolated from xenogeneic and autologous perfused blood samples by gradient centrifugation using Ficoll-Paque (GE Healthcare, Glattbrugg, Switzerland) the morning following the end of the perfusion, typically at midnight. Thereafter, the cells were extensively washed with PBS, counted and split for flow cytometry staining. A sample was stained with LIVE/DEAD ${ }^{\circledR}$ Fixable Aqua Dead Cell Stain according to manufacturer's instructions (Life Technologies, Basel, Switzerland). In some samples reduced PBMC numbers or a high degree of hemolysis was noted (Supplementary Table 1).

Estimates of cell number changes. Absolute numbers of total viable hCD45 cells, hCD45 lymphocytes, and NK cells $\left(\mathrm{CD} 3^{-} \mathrm{CD} 56^{+}\right)$were calculated using the amount of PBMC (cells/ml of blood) purified from each blood sample (Supplemental Table 1) and the corresponding cell percentages obtained by flow cytometry and gating of the respective cell population. The absolute cell 
numbers were used to determinate the relative percentage of the drop of cell numbers compared to base line (BL) values.

Cell surface phenotype analysis by flow cytometry. The characteristics of the antibodies used for flow cytometry analysis are listed in Table 1. For staining, cells were incubated for 30 min at $4^{\circ} \mathrm{C}$ with saturating amounts of directly fluorochrome-labeled antibodies in PBS containing $1 \%$ bovine serum albumin. Secondary polyclonal goat anti-mouse antibody was used for indirect staining (IgG-PE, Poly4053, Biolegend). All analyses were performed using isotype-matched control antibodies. The Attune (Life Technologies) flow cytometer was used for data acquisition, and FlowJo software, version X.0.7 (TreeStar Inc, Ashland, OR, USA) for data analysis. Gating strategy for human cell populations is depicted in Supplementary Figure 1. For the characterization of pig cells a panel of anti-pig antibodies was used (Table 1). Of note, some but not all of the anti-monocyte/macrophage pig markers were cross-reactive with human cells (Supplementary Figure 3). However, since the key panleukocyte marker CD45 was clearly species-specific, misinterpretation of data was excluded.

Immunofluorescence. Snap-frozen biopsies from six wt and six HLA-E/hCD46 transgenic limbs were collected before and at the end of the perfusions (720 min) (a total of 24 biopsies), cut into 5- $\mu \mathrm{m}$ thick sections, air-dried, and stored at $-80^{\circ} \mathrm{C}$ until analysis. After fixation with acetone and re-hydration, the sections were stained with anti-human NKp46 (2 $\mu \mathrm{g} / \mathrm{ml}$, clone 195314, R\&D Systems, Zug, Switzerland), a marker previously shown to identify human NK cells in frozen biopsies [37], by indirect immunofluorescence using goat anti-mouse IgG conjugated with Alexa Fluor ${ }^{\circledR} 546$ (Molecular Probes, Carlsbad, CA, USA) as secondary antibody. Nuclei were stained using 4',6-diamidino-2phenylindole (DAPI, Boehringer, Ingelheim, Germany). The slides were analyzed using a DMI4000 B fluorescence microscope (Leica, Heerbrugg, Switzerland) in different fields. At BL one field was analyzed in $5 \mathrm{wt}$ and 6 CD46/HLA-E tg limb biopsies. Whereas at the end point, 1-3 fields per biopsy from independent wt perfusions and two fields per biopsy in the case of CD46/HLA-E tg limb perfusions were acquired. In summary, at BL five fields were obtained from five different wt animals; and six fields from six different CD46/HLA-E animals; whereas at the end point a total of 11 fields were analyzed from 6 different wt biopsies and 12 fields from six different CD46/HLA-E tg limps. Fluorescence intensity quantification was measured as raw integrated density by Image $\mathrm{J}$ software (version 10.2, National Institutes of Health) on non-manipulated TIFF images [38,39].

Cells. Primary pEC were derived from pigs of different genetic background (wild-type, wt; hCD46; and HLA-E/hCD46 double transgenic animals; respectively, see Weiss et al. [24]). Cells were cultured This article is protected by copyright. All rights reserved 
in DMEM/GlutaMAX ${ }^{\mathrm{TM}}$ medium (Gibco-BRL, Basel, Switzerland) supplemented with 10\% heat inactivated fetal calf serum (Sigma, Buchs, Switzerland), $100 \mathrm{U} / \mathrm{ml}$ Penicillin, $100 \mu \mathrm{g} / \mathrm{ml}$ Streptomycin (Gibco-BRL), and $0.8 \%$ endothelial cell growth medium II supplement mix (PromoCell, Baar, Switzerland) in a humidified atmosphere, at $37^{\circ} \mathrm{C}$ and $5 \% \mathrm{CO}_{2}$. Polyclonal human NK cells were purified from four different healthy donors by negative magnetic bead selection according to the manufacturer's instructions (Miltenyi, Bergisch Gladbach, Germany), and expanded in the presence of 100U/mL IL2 as previously described [8].

Direct NK cytotoxicity. Cytotoxicity was analyzed using the non-radioactive Delfia assay (Perkin Elmer, Schwerzenbach, Switzerland) according to the manufacturer's instructions [40]. IL2-expanded human NK cell lines were used as effector cells. Target cells consisted of primary pEC derived from human CD46 (hCD46) tg, HLA-E/hCD46 double tg or wt pigs. Labeling of cells with the nonradioactive BAFTA was previously optimized. Specific target cell lysis was calculated by subtracting background lysis (spontaneous lysis) of target cells in the absence of effector cells and the maximum release (100\%) induced by detergent (triton X-100) according to the following formula:

$$
\text { Specific lysis }(\%)=\frac{(\text { experimental }- \text { spontaneous })}{(\text { maximun }- \text { spontaneous })} \times 100
$$

Different effector to target ratios (E:T) were examined in 2 hours assay.

Statistical analysis. Analysis was performed using GraphPad software, version 6 (GraphPad, La Jolla, CA, USA). Two-way ANOVA (considering pig genetic background and perfusion time as analysis factors) followed by multiple comparisons, was performed in time course experiments. For in vitro functional assays, a one-way ANOVA was used. Sidak's multiple comparison post-test was applied comparing groups at given perfusion time points. Significance is indicated by: *** extremely significant, $\mathrm{p}<0.001 ; * *$ very significant, $\mathrm{p}<0.01$; $*$ significant, $\mathrm{p}<0.05$; and ns not significant, $\mathrm{p} \geq 0.05$.

\section{RESULTS}

Total white blood cell counts do not decrease during xenoperfusion. Perfusion of wt pig limbs with human blood did not induce significant changes of total WBC counts (Figure 1A). In contrast, when human blood was used to perfuse HLA-E/hCD46 tg pig limbs we noted a significant increase of WBC counts after $720 \mathrm{~min}$ (from $4.9 \times 10^{3}$ to $11.6 \times 10^{3} / \mu 1, \mathrm{p}<0.05$ ). A small albeit statistically significant This article is protected by copyright. All rights reserved 
difference in WBC counts was detected between wt and tg limbs ( $\mathrm{p}=0.0388)$. Control autologous perfusions with pig blood did not show an increase of total WBC counts, although the blood of tg animals contained higher levels of WBC at BL (Supplementary Figure 2).

Rapid consumption of circulating human leukocytes during xenoperfusion. To directly address the question whether human leukocytes decreased and were replaced by porcine cells during xenoperfusions, PBMC obtained from serial blood samples were analyzed by flow cytometry. The percentages of hCD45 cells in the viable PBMC gate revealed a striking drop over time $(\mathrm{p}<0.001)$ with a small, albeit statistically significant difference $(\mathrm{p}=0.0229)$ between limbs from wt and HLA-E/hCD46 pigs (Figure 1B, left plot). At base-line (BL), nearly $90 \%$ of the viable cells stained positive for hCD45, whereas after 720 min the percentage of hCD45 PBMC was below 14\%. This decrease became highly significant compared to BL after 60 min of perfusion of HLA-E/hCD46 tg pig limbs (p<0.001), in contrast the difference was already highly significant after only $10 \mathrm{~min}$ of perfusion of wt limbs $(\mathrm{p}<0.001)$. Next, we compared the absolute numbers of hCD45 cells over time (Figure 1B, middle plot), and calculated the relative drop of total hCD45 cells compared to BL (Figure 1B, right plot). For the relative drop of total hCD45 cells no differences were found at any time-point between xenoperfusions of limbs from wt or HLA-E/hCD46 tg pigs. Moreover, human lymphocytes defined as $\mathrm{SSC}^{\text {low }} / \mathrm{hCD} 45 \mathrm{PBMC}$ declined in a similar manner as hCD45 cells (Figure 1C). Plotting of hCD45 versus SSC illustrated the presence of more granular human cell populations including monocytes, contaminating neutrophils, and presumably early apoptotic cells, as well as cells of non-human origin appearing during xenoperfusions (Figure 1D). The quality of several blood samples, especially after many hours of perfusion, was compromised and showed signs of hemolysis and cell aggregates. Consequently, the numbers and purity of the recovered cells after Ficoll isolation revealed significant variations of neutrophil contaminations and apoptotic cells (Supplementary Table 1 and data not shown).

Recruitment of NK cells during xenoperfusion. One of the major aims of this study was to investigate whether the expression of HLA-E protects the endothelium of the perfused limbs from NK cell recruitment and NK cell-mediated damage, as previously demonstrated in vitro [24]. Therefore, $\mathrm{NK}$ cell percentages, defined by $\mathrm{CD}^{-} \mathrm{CD}^{+} 6^{+}$expression in the viable lymphocyte gates, and absolute NK cell numbers, calculated as described in the material and methods section, were analyzed during pig limb perfusions and compared to the BL values. Due to the random assignment of the blood, HLAE/hCD46 tg pig limb perfusions were in most cases performed with a higher initial percentage and 
overall higher numbers of NK cells (Figure 2A). The percentage of NK cells revealed a striking drop over time (Figure 2B, left plot). Next, we analyzed the absolute numbers of NK cells during perfusion (Figure 2B, middle plot), and calculated the relative drop of NK cells compared to BL (Figure 2B, right plot). These data showed a significant difference in the early consumption of circulating NK cells between wt and HLA-E/hCD46 tg limbs 10 min after xenoperfusion (p<0.001). At 720 min an almost complete absence of human NK cells was noted, without any difference between wt and HLAE/hCD46 tg limb perfusions. Similar results were obtained when the absolute NK cells numbers were estimated using the results of WBC counts obtained by Sysmex system (data not shown). In brief, NK cells disappeared quickly from the circulation, slightly more rapidly during xenoperfusions of wt as compared to HLA-E/hCD46 tg pig limbs.

Reduced recruitment of human NK cells into HLA-E/hCD46 transgenic pig muscle tissue. To determine the fate of the human NK cells which disappeared from the circulation during xenoperfusions, snap-frozen muscle biopsies taken at BL and the end-point at 720 min were analyzed by immunohistochemistry using the NK cell marker NKp46. As compared to CD56, NKG2A, and NKG2D, NKp46 (NCR1) is by far the best tissue NK cell marker reported in the literature. Whereas BL samples revealed only background staining, infiltrating NK cells were demonstrated after 720 min of perfusion (Figure 3A). Quantification of these NKp46 positive cells at 720 min using Image $\mathbf{J}$ software indicated lower recruitment of $\mathrm{NK}$ cells into HLA-E/hCD46 tg limbs as compared to wt pig limbs $(\mathrm{p}<0.05)$, however, more damaged wt tissue might have given rise to higher unspecific background staining (Figure 3B).

Human NK cytotoxicity against pig endothelial cells derived from HLA-E/hCD46 double and hCD46 single transgenic pigs. To evaluate the relative effect of HLA-E and hCD46 expression on xenogeneic NK cytotoxicity, lysis of primary pEC isolated from pigs of different genetic background was tested. A representative experiment and pooled data from 3 independent experiments performed at E:T ratios from 40:1 to 5:1 are shown (Figure 4). No differences were observed between the lysis of wt and hCD46 single tg pEC, however, HLA-E/hCD46 double tg pEC were partially protected from NK cytotoxicity. Overall, the difference of NK cytotoxicity found between pEC targets of wt versus HLAE/hCD46 tg origin was highly significant, with $64.3 \%$ less NK cytotoxicity compared to wt $(\mathrm{p}<0.001)$, whereas lysis of hCD46 tg pEC did not differ from lysis of wt pEC. Thus, hCD46 expression on pEC did not alter human anti-pig xenogeneic NK cytotoxicity, whereas expression of HLA-E in 
combination with hCD46, reduced the lysis of pEC equally to HLA-E expression alone, as previously shown [19-24].

Emergence of pig cells into the circulation during perfusion. Next, hCD $45^{\text {neg }}$ cells of non-human origin were analyzed in blood samples taken at BL and $180 \mathrm{~min}$ by staining with a panel of antibodies directed at pig surface markers. Indeed, after 180 min of xenoperfusion, pig CD45 positive (pCD45) PBMC were detected, as shown in a representative experiment in Figure 5A. To further characterize the phenotype of these cells, viable PBMC were gated as shown in Figure 5B. Three pCD45 cell populations, all of them negative for hCD45, were defined and distinguished according to their cellular granularity: (A) low granularity cells corresponding to pig lymphocytes (48\%); (B) intermediate granularity cells corresponding to pig monocytes (33\%); (C) and high granularity cells corresponding to pig granulocytes $(14 \%)$, respectively. The phenotyping results of these populations are presented as percentages of expression in Table 2.

Population A, strongly resembling lymphocytes according to pCD45 versus SSC plotting, was predominantly positive for pig MHC class I (SLA-I, 88\%), and expressed variable amounts of lymphocyte subset markers corresponding to $\mathrm{T}$ cells $\left(\mathrm{CD}^{+} \mathrm{a}^{+}, 21 \%\right)$, NK cells (pCD16 $\left.{ }^{+} \mathrm{CD} 172 \mathrm{a}^{-}, 10 \%\right)$ [41], and a B-cell subpopulation $\left(\mathrm{CD}^{2} \mathrm{a}^{+}, 9 \%\right)$. There was a modest contamination of myeloid cells, monocytes and granulocytes, respectively $\left(\mathrm{CD}_{14}{ }^{+}, 2.7 \%\right.$; $\mathrm{CD}_{11 \mathrm{R}} 3^{+}, 2.7 \%$; pCD172a $\left.{ }^{+}, 13 \%\right)$. However, this analysis did not account for approximately $40 \%$ of the cells present in population $\mathrm{A}$.

Population B, strongly resembling monocytes based on pCD45 versus SSC plotting, was predominantly positive for pig MHC class I (SLA-I, 83\%), the myeloid markers CD11R3 (76\%), pCD14 (84\%), and exhibited double expression of pCD16 and CD172a (82\%). In addition, this population contained small numbers of circulating porcine endothelial cells which were double positive for pCD106 and CD31 (8.6\%).

Population $\mathrm{C}$, with the highest granularity, was positive for pig granulocyte markers including CD11R3 (75\%); pCD172a (99\%); only subsets of these granulocytes expressed pCD16 ${ }^{+}(54 \%)$ and $\mathrm{pCD}^{+}$ $(65 \%)$, respectively. Intriguingly, $43 \%$ of the cells were SLA-I negative, indicating either the presence of MHC class I negative granulocytes, the loss or low expression of this marker, or technical staining artifacts. Furthermore, staining for circulating $\mathrm{pCD} 106^{+} \mathrm{CD} 31^{+}$porcine endothelial cells was detected on $7 \%$ of the cells. 
In conclusion, the large majority of the pig cells emerging during limb perfusions expressed various lymphocyte subsets and myeloid markers, whereas only a small percentage represented endothelial cells.

\section{DISCUSSION}

The primary aim of the current study was to test the potential of transgenic HLA-E expression on pig endothelial cells to control human NK cell recruitment during ex vivo pig limb xenoperfusions. Early studies with rat and pig hearts perfused with human blood or lymphocytes demonstrated recruitment of human NK cells into the xenoperfused hearts [25,42], and were supported later by the findings of xenoperfused pig kidneys [26,27]. Of note, the current xenoperfusion model is performed on pig limbs expressing alpha-Gal xenoantigen. To control xenoantibody-mediated endothelial damage via complement activation, pigs transgenic for human CD46 in addition to HLA-E were usedas previously reported [35]. In the latter experiments, xenoperfusions of HLA-E/hCD46 double tg limps were characterized by less complement deposition and endothelial cell activation, as shown by E-selectin and VCAM-1 expression; and preserved endothelial integrity, as shown by heparin sulfate proteoglycan and VE-cadherin staining. Compared to wt limps, HLA-E/hCD46 tg porcine tissue was

partially protected from tissue damage and xenoperfusion-induced apoptosis, as demonstrated in muscle biopsies at the end-point $(720 \mathrm{~min})$. Furthermore, the release of inflammatory porcine cytokines, including IL1 $\beta$, IL6, IL8, and thrombin antithrombin complexes, into the plasma, was lower when HLA-E/hCD46 limbs were perfused [35].

In the present study we show that the numbers of circulating hCD45 cells rapidly decreased during xenoperfusions. Further characterization of the fate of hCD45 subpopulations by flow cytometry revealed a faster removal of NK cells from the circulation at early time points during perfusion of wt limbs, as compared to HLA-E/hCD46 tg limb perfusions. These findings were corroborated by the analysis of end-point muscle biopsies, demonstrating a lower density of NK cell infiltration in HLAE/hCD46 tg limbs. In the latter experiments the cellular marker to characterize human NK cells infiltrating pig tissues was carefully chosen. The conventional NK cell marker CD56 was immediately discarded as it is expressed in muscle tissue and there might be cross-reactivity between species. NKp46 (NCR1) is by far the best tissue NK cell marker reported in the literature [43], and a protocol to stain snap frozen tissue is available. In general, all NK cells express NKp46; at least 80\% are NKp $46^{\text {bright }}$ and the other $20 \% \mathrm{NKp} 46^{\text {dull }}$. As to NKG2A and NKG2D, tissue staining protocols have 
not been established and they are less specific for NK cells since also expressed on CD8 T cells. Double tissue staining, although of potential interest, were not envisioned for this study due to a lack of established protocols. Finally, a small number of NKp46 positive cells were detected in pig heart biopsies stemming from healthy hearts or myocardial infarction experiments and muscle biopsies taken at the end point of pig limbs perfused with autologous blood in areas of tissue damage but not in healthy tissues. The anti-NKp46 antibody clone 195314 used for tissue staining demonstrated crossreactivity with porcine lymphocytes (data not shown). However, the intensity of $\mathrm{NKp}^{+} 6^{+}$staining on damaged tissue was much lower than after xenoperfusions and the numbers of circulating pig NK cells did not differ between wt and tg perfusions (table 2 and data not shown). Thus, our observation in xenoperfusion experiments of significantly lower numbers of $\mathrm{NKp}_{4} 6^{+} \mathrm{NK}$ cells in muscle biopsies from hCD46/HLA-E transgenic limbs perfused with human blood compared to wt-limbs indicates that hCD46/HLA-E expression inhibits human NK cell infiltration predominantly directly and to a minor degree due to the prevention of tissue damage and consequent non xeno-related pig/human NK cell infiltration. Taken together, HLA-E expression slightly delayed the recruitment, and ultimately decreased tissue infiltration of human/porcine NK cells into pig limb tissues after $12 \mathrm{~h}$ of perfusion.

There are several limitations of the current study including the lack of hCD46 single transgenic forelimb perfusions as controls. However, in vitro data by us and others did not show any effect of CD46 expression on NK cytotoxicity against pEC. Importantly, a recently published ex vivo pig lung xenoperfusion study by Laird et al corroborates our findings by clearly showing physiologically meaningful protection from NK cell-mediated damage by GalTKO.hCD46.HLA-E expression using GalTKO.hCD46 lungs as control [28]. In addition reduced NK cell recruitment was also observed in the Munich heart model [29,30]. Moreover, due to the restricted volume of blood donations, we could not perfuse both wt and HLA-E/hCD46 tg pig limbs in parallel with blood obtained from the same donor. Since the proportion of NK cells within the lymphocyte population $(0.61-16.87 \%)$ varies enormously among healthy donors [44], we analyzed the relative drop of NK cell numbers. For the same reason quantitative analysis of tissue infiltration by NK cells was difficult to interpret. However, despite the fact that HLA-E/hCD46 tg pig limbs were in general perfused with blood containing higher numbers of NK cells, we observed less NK cell tissue infiltration using NKp46 staining of frozen sections, although the software used quantifies fluorescence intensity, rather than counting individual NK cells. 
By all means, our findings beg the question: where are these NK cells which disappeared completely from the circulation after 720 min of perfusion? In contrast to HLA-G, HLA-E does not affect adhesion of human NK cells to pEC, as shown in static and dynamic adhesion assays $[13,23,28]$. In addition, we have previously reported that transmigration of human NK cells through pig endothelium depends on hCD49d-pCD106 interactions [45], and on hCD99 interactions with so far unknown ligands expressed by $\mathrm{pEC}$ [46]. In the light of reduced endothelial cell activation during HLA-E/hCD46 tg compared to wt pig limb xenoperfusion [35], which was associated with lower expression of pCD106, we hypothesize that human NK cells might adhere to the vascular lining of HLA-E/hCD46 tg pig limbs, but transmigrate to a lesser extent into these tissues. Finally, the relative percentages of human B-and T-lymphocytes showed no major differences between wt and HLA-E/hCD46 tg xenoperfusions (data not shown), with a reduction of B-cells after three hours of perfusion, as reported previously in a model of short-term kidney xenoperfusion [26].

Although there are major differences in terms of endothelial damage during short term xenoperfusions reported in the literature, in part because different pig organs were employed [47-51], and the exact contribution of NK cells is unknown, the expression of HLA-E might reduce endothelial damage by preventing NK cell activation. We cannot directly support this hypothesis with experimental data from our model, since the functional assays originally planned with circulating NK cells obtained during xenoperfusions could not be performed due to very low NK cell numbers. However, in agreement with previous work [19,20,22,24,28], human anti-pig NK cytotoxicity assays, performed in vitro using pEC derived from tg animals as targets, confirmed that HLA-E provided partial protection, whereas the expression of hCD46 had no effect. Furthermore, since NK cells are able to perform FcR-mediated ADCC and neutrophils/macrophages eliminate antibody-coated cells, differences in xenoreactive antibody levels in the blood donors and differential binding to the tg endothelium might have influenced the results. Previous data of the same study have shown that overall human $\operatorname{IgM}$ and $\operatorname{IgG}$ natural xenoreactive antibodies bind equally to the endothelia of both, wt and hCD46/HLA-E pig limps after 12 hours of perfusion [33]. However, since the levels of natural xenoantibodies in the donor blood samples were not measured we cannot exclude that differences might have had an impact on NK cellmediated ADCC and tissue damage.

To date most studies have focused on the tissue recruitment of human leukocytes in ex vivo xenoperfusion models. Perfusion of pig lungs with human blood, for instance, showed a quick drop in WBC counts [52,53], in particular for monocytes and neutrophils; both in wt animals [51,54], but also 
using genetically modified animals [53]. Similar finding were reported for kidney and liver xenoperfusions [26,49,55-58]. In contrast, scarce information is available concerning the release of pig cells. An early publication indicated that porcine leukocytes, mainly lymphocytes, were released from pig kidneys during buffered-saline perfusion [59]. In addition, an increase in WBC counts was also observed during perfusions of pig hearts, although the nature of this rise was not further characterized [60]. At last, perfusion of pig lungs with different perfusion solutions showed the release of pig T- and B-lymphocytes as well as monocytes, macrophages and dendritic cells [61]. In summary, the nature of porcine cells released during xenoperfusion of different organs remains poorly characterized.

In our model of pig limb perfusion the total circulating leukocyte counts did not decrease as measured by Sysmex not distinguishing between cells of human and pig origin. In contrast, hCD45 PBMC disappeared rapidly from the circulation, presumably due to recruitment and tissue infiltration. Thus, we hypothesized that pig cells were released into the circulation. Indeed, cells of pig origin were detected in the circulation using species-specific cell markers. First, we speculated that these pig cells might correspond to $\mathrm{pEC}$ released upon damage of the endothelium during xenoperfusion. Nonetheless, only a small percentage of these cells were of endothelial origin as shown by $\mathrm{pCD} 106^{+} \mathrm{CD} 31^{+}$ expression. Instead, the large majority of the emerging pig cells expressed various lymphocyte and myeloid markers (CD172a, SIRP $\alpha$, SWC3). Moreover they were highly positive for SLA-I and pCD45, indicating that they belonged to the leukocyte lineage [62-64]. Despite flushing of the pig limbs for 5 min with hydroxyethyl starch before perfusion, these pig cells might have been released from the marginal vascular pool into the bloodstream by detachment from the endothelial lining. Alternatively, pCD45 cells might have been released from the pig bone marrow, since in contrast to organ perfusions; several bones are present in the pig forelimb model (humerus, radius, ulna and metacarpals). Lineage negative immature bone marrow cells might also explain the presence in the lymphocyte gate of approximately $40 \%$ SLA-I $^{+}$pig cells that are not accounted for by staining with our antibody panel. In conclusion, the release of pig cells needs further investigation in xenoperfusion models of organs foreseen for clinical transplantation, e.g. heart, kidney or lung. Depending on the phenotype and antigen-presenting properties of these cells, even the release of much lower numbers into the circulation following transplantation has major implications for the development of acquired immune xenoresponses and/or tolerance [65-67]. The protocols for flushing pig organs prior to perfusion or transplantation in order to remove cells might have to be optimized to minimize xenorejection. 
In conclusion, the current work showed that HLA-E/hCD46 double tg pig limb perfusion is characterized by slightly delayed NK cell recruitment and reduced tissue infiltration. In addition, we describe and characterize a cell population of pig origin that was released into the circulation during the limb perfusions.

\section{FIGURE LEGENDS}

Figure 1. Time-course of circulating human CD45 positive leukocytes during perfusion. Blood samples were taken at predefined time points during ex vivo xenoperfusions. (A) Pooled data of total WBC counts as quantified by the Sysmex system during 6 wt and 6 HLA-E/hCD46 tg pig limb xenoperfusions are shown. The difference of total WBC counts in xenoperfusions between wt and HLA-E/hCD46 tg pig limbs was slightly significant, p<0.0388, when tested by 2-ways ANOVA. (B) For flow cytometry, PBMC were isolated and stained for viability followed by monoclonal antibody staining. The gating strategy for the analysis of viable human CD45 (hCD45) PBMC is shown in Supplementary Figure 1. Pooled data of the percentages of hCD45 PBMC (left plot); of the absolute numbers of hCD45 cells (middle plot); and the percentages of the drop of hCD45 cells numbers compared to base line values (right plot) are shown over time. (C) Pooled data of the percentages of human lymphocytes (left plot); of the absolute numbers of human lymphocytes (middle plot); and the percentages of the drop of human lymphocytes numbers compared to base line values (right plot) are shown over time. Data are shown as mean+SEM of $6 \mathrm{wt}$ and 5 HLA-E/hCD46 pig limb perfusions. Wild-type (wt) limbs are shown with open circles (०), whereas HLA-E/hCD46 with filled circles (•). Differences between wt and HLA-E/hCD46 tg were obtained using 2-way ANOVA analysis. Sidak's multiple comparison post-test was applied comparing groups at given perfusion time points. Significance is indicated by: $* * *$ extremely significant, $\mathrm{p}<0.001$; ** very significant, $\mathrm{p}<0.01$; $*$ significant, $\mathrm{p}<0.05$. (D) Representative hCD45 and side scatter (SSC) flow cytometry plots during a HLA-E/hCD46 tg pig limb xenoperfusion are shown. Thick lined rectangles indicate total hCD45 cells, ovals lymphocytes; the respective percentages are given as numbers.

Figure 2. Human NK cells are quickly removed from the circulation during xenoperfusion. Blood samples were taken at predefined time points during ex vivo xenoperfusions. PBMC were isolated and stained for viability followed by monoclonal antibody staining. (A) The percentages (left plot) and absolute numbers (right plot) of $\mathrm{CD}^{-} \mathrm{CD}^{-} 6^{+} \mathrm{NK}$ cells at base-line (BL) of wt (open diamonds, $\left.\diamond\right)$ and HLA-E/hCD46 tg (filled diamonds, $\diamond$ ) xenoperfusions are shown, indicating the variability among 
different blood donors. The difference was tested by t-test $(\mathrm{p}=0.052)$. (B) Pooled data of the percentages of NK cells (left plot); of the absolute numbers of NK cells (middle plot); and the percentages of the relative drop of NK cell numbers compared to BL values (right plot) are shown over time. Pooled data are shown from 4 and 3 xenoperfusions for wt and HLA-E/hCD46 pig limbs, respectively. Data shown as mean + SEM. Wild-type (wt) limbs are shown with open circles (O), whereas HLA-E/hCD46 with filled circles (•). Differences between wt and HLA-E/hCD46 tg were obtained using 2-way ANOVA analysis. Sidak's multiple comparison post-test was applied comparing groups at given perfusion time points. Significance is indicated by: $* * *$ extremely significant, $\mathrm{p}<0.001$; ** very significant, $\mathrm{p}<0.01$.

Figure 3. Recruitment of human NK cells in pig muscle tissue. Muscle biopsies from wt and HLAE/hCD46 tg pig limbs were obtained at BL and at the end-point (720 min) of the xenoperfusions and snap-frozen until analysis. NK cells were stained using the specific NK cell surface marker NKp46 followed by secondary goat anti-mouse Alexa Fluor ${ }^{\circledR} 546$ (red), whereas nuclei were revealed with DAPI (blue). (A) Representative images from biopsies taken at BL and end-point in wt and HLAE/hCD46 double tg limbs are shown. White bars correspond to $75 \mu \mathrm{m}$. (B) Quantification of fluorescence intensity of integrated density (y-axe) analyzed by Image J software on non-manipulated raw TIFF images (11 different fields for each type of limbs, wt and tg, at end-point and 5 different fields at BL). Data shown as mean + SEM, and two-way ANOVA analysis followed by multiple comparisons showed $*$ significant differences $\mathrm{p}<0.05$ between groups.

Figure 4. HLA-E expression but not hCD46 expression on pig endothelial cells provides partial protection against xenogeneic human NK cytotoxicity in vitro. (A) Porcine endothelial cells (pEC) derived from wt; hCD46 and HLA-E/hCD46 tg animals were labeled and used as target cells in $2 \mathrm{~h}$ non-radioactive Delfia cytotoxicity assays using polyclonal human NK cell lines as effector cells. Data of one representative experiment are presented at different effector to target (E:T) ratios showing mean values \pm SD of triplicates. Specific target cell lysis was calculated by subtracting background lysis of target cells in the absence of effector cells and the maximum release (100\%) induced by detergent (triton X100) according to the formula provided in the material and methods. (B) Pooled data from three independent experiments with mean + SEM are shown; one-way ANOVA analysis revealed a 
*** highly significant difference, $\mathrm{p}<0.005$, of the relative inhibition of NK lysis against HLA-E/hCD46 tg pEC target cells as compared to wt $\mathrm{pEC}$.

Figure 5. Pig cells are released into the circulation during xenoperfusion. Whole blood samples were taken at different time points during xenoperfusion; peripheral blood mononuclear cells (PBMC) were isolated and stained for viability followed by monoclonal antibody staining. (A) Representative plots of pig CD45 (pCD45) and human CD45 (hCD45) versus side scatter (SSC) are shown for the analysis of PBMC coming from the same experiment isolated at two different time points: base-line (BL) and 180 min after starting the xenoperfusion of a HLA-E/hCD46 forelimb. (B) Gating strategy used for flow cytometry analysis of pig marker expression during xenoperfusion at time-point $180 \mathrm{~min}$. Cells were first gated for viability by plotting forward scatter (FCS) versus LIVE/DEAD ${ }^{\circledR}$ Fixable Aqua Dead Cell stain (left plot). Viable cells were next plotted for hCD45 versus pCD45 to discard cell conjugates and cellular debris, and select only pCD45 single positive cells (middle plot). Finally, pCD45 versus SSC plot was generated and pig cells populations defined on the base of their cytometric properties, referred to as population $\mathrm{A}, \mathrm{B}$, and $\mathrm{C}$, respectively (right plot), from which different pig markers were further analyzed as shown in Table 2.

SOURCE OF FUNDING: Swiss National Science Foundation (\#320030_138376 and 3200B0_109921 to JDS and \#32003B_135272 and \# 32003B_138434 to RR), in addition to a Private Foundation and the German Research Foundation (TRR127).

ACKNOWLEDGEMENTS: The authors would like to thank to L. Gruaz, L. Papadayachi and J. Pimenta for their technical help.

CONFLICT OF INTEREST: The authors of this manuscript declare no conflicts of interest to disclosure with the exception of DA who works for Revivicor Inc.

CONTRIBUTION: GPY provided research design, performed flow cytometry data acquisition, interpretation of data and wrote the manuscript; AKB participated blood sampling and 
immunofluorescence analysis; AP conceptually designed and set-up the flow cytometry experiments and data analysis, drafting of the paper; NM contributed with cytotoxicity experiments; MP substantial contribution for flow cytometry data acquisition; DA provided primary cells from human CD46 transgenic pigs for nuclear transfer experiments; EW, NK, AB produced HLA-E/hCD46 pigs and multi-engineered pigs; $\mathrm{EV}$ and $\mathrm{MAC}$ participated in the concept and design of the animal experimentation; HJ and DK participated in performing the animal experimentation; RR participated in the concept and design of the study and critical review; JDS provided research design, participated in interpretation of data and writing of the manuscript, approval of the final submitted version.

\section{REFERENCES}

1. COOPER DK, EZZELARAB MB, HARA H, et al. The pathobiology of pig-to-primate xenotransplantation: a historical review. Xenotransplantation 2016; 23: 83-105.

2. GRIESEMER A, YAMADA K, SYKES M. Xenotransplantation: immunological hurdles and progress toward tolerance. Immunol Rev 2014; 258: 241-258.

3. VADORI M, COZZI E. Immunological challenges and therapies in xenotransplantation. Cold Spring Harb Perspect Med 2014; 4: a015578.

4. SATYANANDA V, HARA H, EZZELARAB MB, et al. New concepts of immune modulation in xenotransplantation. Transplantation 2013; 96: 937-945.

5. WATZL C. How to trigger a killer: modulation of natural killer cell reactivity on many levels. Adv Immunol 2014; 124: 137-170.

6. SULLIVAN JA, OETTINGER HF, SACHS DH, EDGE AS. Analysis of polymorphism in porcine MHC class I genes: alterations in signals recognized by human cytotoxic lymphocytes. J Immunol 1997; 159: 2318-2326.

7. KWIATKOWSKI P, ARTRIP JH, JOHN R, et al. Induction of swine major histocompatibility complex class I molecules on porcine endothelium by tumor necrosis factor-alpha reduces lysis by human natural killer cells. Transplantation 1999; 67: 211-218.

8. SEEBACH JD, COMRACK C, GERMANA S, et al. HLA-Cw3 expression on porcine endothelial cells protects against xenogeneic cytotoxicity mediated by a subset of human NK cells. J Immunol 1997; 159: 3655-3661.

This article is protected by copyright. All rights reserved 
9. SASAKI H, XU XC, SMITH DM, HOWARD T, MOHANAKUMAR T. HLA-G expression protects porcine endothelial cells against natural killer cell-mediated xenogeneic cytotoxicity. Transplantation 1999; 67: 31-37.

10. DORLING A, MONK NJ, LECHLER RI. HLA-G inhibits the transendothelial migration of human NK cells. Eur J Immunol 2000; 30: 586-593.

11. FORTE P, MATTER-REISSMANN UB, STRASSER M, SCHNEIDER MK, SEEBACH JD. Porcine aortic endothelial cells transfected with HLA-G are partially protected from xenogeneic human NK cytotoxicity. Hum Immunol 2000; 61: 1066-1073.

12. MATSUNAMI K, MIYAGAWA S, NAKAI R, MURASE A, SHIRAKURA R. The possible use of HLA-G1 and G3 in the inhibition of NK cell-mediated swine endothelial cell lysis. Clin Exp Immunol 2001; 126: 165-172.

13. FORTE P, PAZMANY L, MATTER-REISSMANN UB, et al. HLA-G inhibits rolling adhesion of activated human NK cells on porcine endothelial cells. J Immunol 2001; 167: 6002-6008.

14. SHARLAND A, PATEL A, LEE JH, et al. Genetically modified HLA class I molecules able to inhibit human NK cells without provoking alloreactive CD8+ CTLs. J Immunol 2002; 168 : 3266-3274.

15. FORTE P, BAUMANN BC, SCHNEIDER MK, SEEBACH JD. HLA-Cw4 expression on porcine endothelial cells reduces cytotoxicity and adhesion mediated by CD158a+ human NK cells. Xenotransplantation 2009; 16: 19-26.

16. STRONG RK, HOLMES MA, LI P, et al. HLA-E allelic variants. Correlating differential expression, peptide affinities, crystal structures, and thermal stabilities. J Biol Chem 2003; 278: 5082-5090.

17. HOSSEINI E, SCHWARER AP, GHASEMZADEH M. Do human leukocyte antigen E polymorphisms influence graft-versus-leukemia after allogeneic hematopoietic stem cell transplantation? Exp Hematol 2015; 43: 149-157.

18. SAUNDERS PM, VIVIAN JP, O'CONNOR GM, et al. A bird's eye view of NK cell receptor interactions with their MHC class I ligands. Immunol Rev 2015; 267: 148-166.

19. SASAKI H, XU XC, MOHANAKUMAR T. HLA-E and HLA-G expression on porcine endothelial cells inhibit xenoreactive human NK cells through CD94/NKG2-dependent and independent pathways. J Immunol 1999; 163: 6301-6305.

20. MATSUNAMI K, MIYAGAWA S, NAKAI R, YAMADA M, SHIRAKURA R. Modulation of the leader peptide sequence of the HLA-E gene up-regulates its expression and down-regulates natural killer cell-mediated swine endothelial cell lysis. Transplantation 2002; 73: 1582-1589.

This article is protected by copyright. All rights reserved 
21. CREW MD, CANNON MJ, PHANAVANH B, GARCIA-BORGES CN. An HLA-E single chain trimer inhibits human NK cell reactivity towards porcine cells. Mol Immunol 2005; 42: 1205-1214.

22. FORTE P, BAUMANN BC, WEISS EH, SEEBACH JD. HLA-E expression on porcine cells: protection from human NK cytotoxicity depends on peptide loading. Am J Transplant 2005; 5: 2085-2093.

23. LILIENFELD BG, CREW MD, FORTE P, BAUMANN BC, SEEBACH JD. Transgenic expression of HLA-E single chain trimer protects porcine endothelial cells against human natural killer cell-mediated cytotoxicity. Xenotransplantation 2007; 14: 126-134.

24. WEISS EH, LILIENFELD BG, MULLER S, et al. HLA-E/human beta2-microglobulin transgenic pigs: protection against xenogeneic human anti-pig natural killer cell cytotoxicity. Transplantation 2009; 87: 35-43.

25. INVERARDI L, SAMAJA M, MOTTERLINI R, et al. Early recognition of a discordant xenogeneic organ by human circulating lymphocytes. J Immunol 1992; 149: 1416-1423.

26. KHALFOUN B, BARRAT D, WATIER H, et al. Development of an ex vivo model of pig kidney perfused with human lymphocytes. Analysis of xenogeneic cellular reactions. Surgery 2000; 128: 447-457.

27. RAMOS A, VEGA A, VAL F, et al. Immunohistochemical study of a new experimental model of acute cellular xenograft rejection. Transplant Proc 2000; 32: 960.

28. LAIRD CT, BURDORF L, FRENCH BM, et al. Transgenic expression of human leukocyte antigen-E attenuates GalKO.hCD46 porcine lung xenograft injury. Xenotransplantation 2017; 24.

29. KUBICKI N, LAIRD C, BURDORF L, et al. The effect of human leukocyte antigen-E expression on GalTKO.hCD46 lung xenograft survival and injury in an ex-vivo xenoperfusion model. Xenotransplantation 2015; 22: S193.

30. ABICHT JM, BONGONI AK, MAYR T, et al. Ex-vivo perfusion of alpha-Gal knockout, CD46/HLA-E double transgenic pig hearts. Xenotransplantation 2015; 22: S184.

31. ABICHT JM, MAYR T, SFRISO R, PUGA YUNG GL, SEEBACH JD, RIEBEN R, et al. Multiple genetically modified GTKO/hCD46/HLA-E/h $\beta 2$ microglobulin porcine hearts are protected from natural killer cell infiltration and preserve myocardial function during ex vivo perfusion with human blood. 2017. Manuscript in preparation. 
32. CONSTANTINESCU MA, KNALL E, XU X, et al. Preservation of amputated extremities by extracorporeal blood perfusion; a feasibility study in a porcine model. J Surg Res 2011; 171: 291-299.

33. BONGONI AK, KIERMEIR D, SCHNIDER J, et al. Transgenic Expression of Human CD46 on Porcine Endothelium: Effect on Coagulation and Fibrinolytic Cascades During Ex Vivo Human-to-Pig Limb Xenoperfusions. Transplantation 2015; 99: 2061-2069.

34. BONGONI AK, KIERMEIR D, JENNI H, et al. Activation of the lectin pathway of complement in pig-to-human xenotransplantation models. Transplantation 2013; 96: 791-799.

35. BONGONI AK, KIERMEIR D, JENNI H, et al. Complement dependent early immunological responses during ex vivo xenoperfusion of hCD46/HLA-E double transgenic pig forelimbs with human blood. Xenotransplantation 2014; 21: 230-243.

36. BONGONI AK, KIERMEIR D, DENOYELLE J, et al. Porcine extrahepatic vascular endothelial asialoglycoprotein receptor 1 mediates xenogeneic platelet phagocytosis in vitro and in human-to-pig ex vivo xenoperfusion. Transplantation 2015; 99: 693-701.

37. HALAMA N, BRAUN M, KAHLERT C, et al. Natural killer cells are scarce in colorectal carcinoma tissue despite high levels of chemokines and cytokines. Clin Cancer Res 2011; 17: 678-689.

38. ABRÀMOFF MD, MAGALHÃES PJ, RAM SJ. Image processing with ImageJ. Biophotonics Int 2004; 11:36-42.

39. SCHNEIDER CA, RASBAND WS, ELICEIRI KW. NIH Image to ImageJ: 25 years of image analysis. Nat Methods 2012; 9: 671-675.

40. BLOMBERG K, HAUTALA R, LOVGREN J, et al. Time-resolved fluorometric assay for natural killer activity using target cells labelled with a fluorescence enhancing ligand. J Immunol Methods 1996; 193: 199-206.

41. SAALMULLER A. Characterization of swine leukocyte differentiation antigens. Immunol Today 1996; 17: 352-354.

42. KIRK AD, HEINLE JS, MAULT JR, SANFILIPPO F. Ex vivo characterization of human antiporcine hyperacute cardiac rejection. Transplantation 1993; 56: 785-793.

43. KRUSE PH, MATTA J, UGOLINI S, VIVIER E. Natural cytotoxicity receptors and their ligands. Immunol Cell Biol 2014; 92: 221-229.

44. ANGELO LS, BANERJEE PP, MONACO-SHAWVER L, et al. Practical NK cell phenotyping and variability in healthy adults. Immunol Res 2015; 62: 341-356. 
45. SCHNEIDER MK, STRASSER M, GILLI UO, et al. Rolling adhesion of human NK cells to porcine endothelial cells mainly relies on CD49d-CD106 interactions. Transplantation 2002; 73: 789-796.

46. SCHNEIDER MK, GHIELMETTI M, RHYNER DM, ANTSIFEROVA MA, SEEBACH JD. Human leukocyte transmigration across Galalpha(1,3)Gal-negative porcine endothelium is regulated by human CD18 and CD99. Transplantation 2009; 87: 491-499.

47. COLLINS BH, CHARI RS, MAGEE JC, et al. Mechanisms of injury in porcine livers perfused with blood of patients with fulminant hepatic failure. Transplantation 1994; 58: 1162-1171.

48. CHARIRS, COLLINS BH, MAGEE JC, et al. Brief report: treatment of hepatic failure with ex vivo pig-liver perfusion followed by liver transplantation. N Engl J Med 1994; 331: 234-237.

49. MAGNUSSON S, STROKAN V, MOLNE J, et al. Blocking of human anti-pig xenoantibodies by soluble GAL alpha 1-3Gal and Gal alpha 1-2Gal disaccharides; studies in a pig kidney in vitro perfusion model. Transpl Int 2000; 13: 402-412.

50. LINKE R, DIEFENBECK M, FRIEDRICH R, SEEHOFER D, HAMMER C. Monitoring of microhemodynamic changes during ex vivo xenogeneic liver perfusion using intravital microscopy. Transpl Int 1998; 11: 259-265.

51. NGUYEN BN, AZIMZADEH AM, SCHROEDER C, et al. Absence of Gal epitope prolongs survival of swine lungs in an ex vivo model of hyperacute rejection. Xenotransplantation 2011; 18: 94-107.

52. KIM HK, KIM JE, WI HC, et al. Aurintricarboxylic acid inhibits endothelial activation, complement activation, and von Willebrand factor secretion in vitro and attenuates hyperacute rejection in an ex vivo model of pig-to-human pulmonary xenotransplantation. Xenotransplantation 2008; 15: 246-256.

53. WESTALL GP, LEVVEY BJ, SALVARIS E, et al. Sustained function of genetically modified porcine lungs in an ex vivo model of pulmonary xenotransplantation. J Heart Lung Transplant 2013; 32: 1123-1130.

54. BURDORF L, STODDARD T, ZHANG T, et al. Expression of human CD46 modulates inflammation associated with GalTKO lung xenograft injury. Am J Transplant 2014; 14: 10841095.

55. FIANE AE, MOLLNES TE, VIDEM V, et al. Compstatin, a peptide inhibitor of C3, prolongs survival of ex vivo perfused pig xenografts. Xenotransplantation 1999; 6: 52-65. 
56. PASCHER A, POEHLEIN C, STORCK M, et al. Immunopathological observations after xenogeneic liver perfusions using donor pigs transgenic for human decay-accelerating factor. Transplantation 1997; 64: 384-391.

57. POHLEIN C, PASCHER A, STORCK M, et al. Transgenic human DAF-expressing porcine livers: their function during hemoperfusion with human blood. Transplant Proc 1996; 28: 770771.

58. REES MA, BUTLER AJ, CHAVEZ-CARTAYA G, et al. Prolonged function of extracorporeal hDAF transgenic pig livers perfused with human blood. Transplantation 2002; 73: 1194-1202.

59. MAGNUSSON S, MANSSON JE, STROKAN V, et al. Release of pig leukocytes during pig kidney perfusion and characterization of pig lymphocyte carbohydrate xenoantigens. Xenotransplantation 2003; 10: 432-445.

60. LEE YT, CHU CH, SUE SH, CHEN IC, WEI J. Efficacy of double filtration plasmapheresis in removing xenoantibodies and prolonging xenograft survival in an ex vivo swine perfusion model. Transplant Proc 2012; 44: 1143-1145.

61. ROMAN M, GJORGJIMAJKOSKA O, NEIL D, et al. Comparison between cellular and acellular perfusates for ex vivo lung perfusion in a porcine model. J Heart Lung Transplant 2015; 34: 978-987.

62. ZUCKERMANN FA, BINNS RM, HUSMANN R, et al. Analyses of monoclonal antibodies reactive with porcine CD44 and CD45. Vet Immunol Immunopathol 1994; 43: 293-305.

63. EZQUERRA A, REVILlA C, ALVAREZ B, et al. Porcine myelomonocytic markers and cell populations. Dev Comp Immunol 2009; 33: 284-298.

64. PIRIOU-GUZYLACK L, SALMON H. Membrane markers of the immune cells in swine: an update. Vet Res 2008; 39: 54.

65. MORELLI AE. Dendritic cells of myeloid lineage: the masterminds behind acute allograft rejection. Curr Opin Organ Transplant 2014; 19: 20-27.

66. TAI HC, ZHU X, LIN YJ, et al. Attempted depletion of passenger leukocytes by irradiation in pigs. JTransplant 2011; 2011: 928759.

67. WOOD KJ. Passenger leukocytes and microchimerism: what role in tolerance induction? Transplantation 2003; 75: 17S-20S. 
Table 1. Antibodies used in phenotype analysis by flow cytometry

\begin{tabular}{lllll}
\hline Specificity & Marker & Clone & Fluorochrome* & Source $\dagger$ \\
\hline Pig & CD1a & $76-7-4$ & PE & SouthernBiotech \\
& CD3a & BB23-8E6 & PE & Novus Biologicals \\
& CD11b (CD11R3) & 2F4/11 & FITC & AbDSerotec \\
& CD14 & MIL2 & FITC & AbDSerotec \\
& CD16 & G7 & PE & AbDSerotec \\
& CD45 & K252-IE4 & FITC, DyLight405 & AbDSerotec \\
& CD106 & 10.2C7 & Purified, PE & Home made \\
& CD172a (SWC3) & BL1H7 & FITC & AbDSerotec \\
& SLA-I & SCR3 & Purified, PE & Home-made \\
& SLA-I & 74-11-10 & Purified & VMRD \\
\hline Pig and human & CD31 & LCI-4 & FITC & AbDSerotec \\
\hline Human & CD45 & HI30 & PerCP-Cy5.5 & Biolegend \\
& CD3 & UCTH1 & AF405 & LifeTechnologies \\
& CD56 & HCD56 & BV605 & Biolegend \\
& CD19 & LT & FITC & Miltenyi \\
\hline
\end{tabular}

Abbreviations: AF405, Alexa Fluor ${ }^{\circledR} 405 ;$ BV605, Brilliant Violet ${ }^{\mathrm{TM}} 605$; FITC, fluorescein isothiocyanate; PE, R-phycoerythrin; PerCP-Cy5.5, peridinin chlorophyll protein-cyanine 5.5

*Directly labeled monoclonal antibodies were used for staining unless otherwise indicated. For indirect staining secondary polyclonal goat anti-mouse antibody was used (IgG-PE, Poly4053, Biolegend).

$\dagger$ Addresses of antibody distributors are as follows: AbDSerotec (Puchheim, Germany); Biolegend (Luzern, Switzerland); Life Technologies (Basel, Switzerland); Miltenyi (Bergisch Gladbach, Germany); Novus Biologicals (Cambridge, UK); Southern Biothech (Allschwil, Switzerland); VMRD (Pullman, WA, USA).

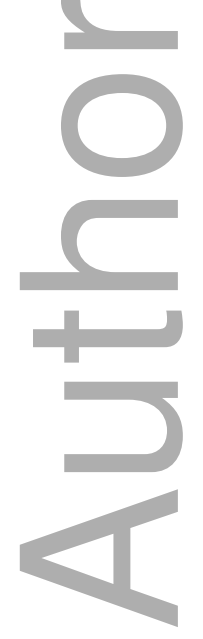

This article is protected by copyright. All rights reserved 
Table 2. Phenotypic characteristics of the pig cell populations appearing during xenoperfusion.

\begin{tabular}{|c|c|c|c|c|}
\hline \multirow[t]{2}{*}{ Marker } & \multirow[t]{2}{*}{$\begin{array}{l}\text { Associated phenotype, alternative } \\
\text { name }\end{array}$} & \multicolumn{3}{|c|}{$\begin{array}{c}\text { Population } \\
\text { Positive cells, \% } \\
\text { (SD) }\end{array}$} \\
\hline & & $\mathbf{A}$ & B & $\mathbf{C}$ \\
\hline $\mathrm{pCD}^{+}{ }^{+}$vs SSC & Pig leukocytes, LCA & $\begin{array}{c}47.7 \\
(14.8)\end{array}$ & $\begin{array}{c}32.8 \\
(10.0)\end{array}$ & $\begin{array}{l}14.3 \\
(8.9)\end{array}$ \\
\hline $\mathrm{SLA}^{+} \mathrm{I}^{+}$ & Pig cells ${ }^{*}$ & $\begin{array}{c}87.6 \\
(18.8)\end{array}$ & $\begin{array}{c}82.6 \\
(18.7)\end{array}$ & $\begin{array}{c}57.2 \\
(21.9)\end{array}$ \\
\hline $\mathrm{CD} 11 \mathrm{R}^{+}$ & Monocyte/granulocyte, possibly CD11b & $\begin{array}{c}2.7 \\
(1.5)\end{array}$ & $\begin{array}{c}77.5 \\
(10.0)\end{array}$ & $\begin{array}{l}74.5 \\
(27.7)\end{array}$ \\
\hline $\mathrm{pCD} 172 \mathrm{a}^{+}$ & Myeloid linage $^{\dagger}$, SIRP $\alpha$ or SWC3 & $\begin{array}{l}13.1 \\
(4.3)\end{array}$ & $\begin{array}{l}88.7 \\
(5.2)\end{array}$ & $\begin{array}{l}99.4 \\
(0.6)\end{array}$ \\
\hline $\mathrm{pCD} 16^{+}$ & Fc $\gamma R 3 A$ & $\begin{array}{c}12.2 \\
(12.3)\end{array}$ & $\begin{array}{l}83.3 \\
(7.0)\end{array}$ & $\begin{array}{c}53.5 \\
(30.2)\end{array}$ \\
\hline $\mathrm{pCD} 14^{+}$ & Monocyte/granulocyte & $\begin{array}{c}2.7 \\
(0.8)\end{array}$ & $\begin{array}{l}84.3 \\
(7.0)\end{array}$ & $\begin{array}{c}64.6 \\
(24.4)\end{array}$ \\
\hline $\mathrm{pCD} \mathrm{a}^{+}$ & $\mathrm{T}_{\text {cell }}^{*}$ & $\begin{array}{c}21.3 \\
(41.6)\end{array}$ & $\begin{array}{c}2.9 \\
(4.0)\end{array}$ & $\begin{array}{l}1.6 \\
(1.8)\end{array}$ \\
\hline $\mathrm{pCD} 1 \mathrm{a}^{+}$ & Fraction of B cells & $\begin{array}{c}9.1 \\
(3.1)\end{array}$ & $\begin{array}{l}7.0 \\
(2.6)\end{array}$ & $\begin{array}{c}4.6 \\
(1.8)\end{array}$ \\
\hline pCD16 ${ }^{+} \mathrm{pCD} 172 \mathrm{a}^{-}$ & NK cells ${ }^{\ddagger}$ & $\begin{array}{c}9.7 \\
(10.9)\end{array}$ & $\begin{array}{l}1.3 \\
(0.0)\end{array}$ & $\begin{array}{l}0.16 \\
(0.0)\end{array}$ \\
\hline $\mathrm{pCD} 16^{+} \mathrm{pCD} 172 \mathrm{a}^{+}$ & Monocytes & $\begin{array}{l}2.6 \\
(1.6)\end{array}$ & $\begin{array}{l}82.0 \\
(6.6)\end{array}$ & $\begin{array}{c}53.5 \\
(30.1)\end{array}$ \\
\hline $\mathrm{pCD} 106^{+} \mathrm{CD} 31^{+}$ & Endothelial cells ${ }^{\S}$ & $\begin{array}{c}2.1 \\
(0.6)\end{array}$ & $\begin{array}{c}8.6 \\
(6.5)\end{array}$ & $\begin{array}{c}7.1 \\
(4.7)\end{array}$ \\
\hline
\end{tabular}

Flow cytometry analysis of PBMC isolated after 180 min of human blood xenoperfusion. Cell populations were gated as described in Figure 5B and percentage of positive cells shown as \% (SD). Data obtained from 4 independent experiments ( $2 \mathrm{wt}$ and 2 tg pig legs).

"Pig cells are SLA-I positive with the exception of red blood cells and platelets

When surface marker is looked up in large and complex populations

When surface marker is looked up in the lymphocyte gate

${ }^{\S}$ When surface markers are looked up in large and complex populations

LCA: leukocyte common antigen

This article is protected by copyright. All rights reserved 
A
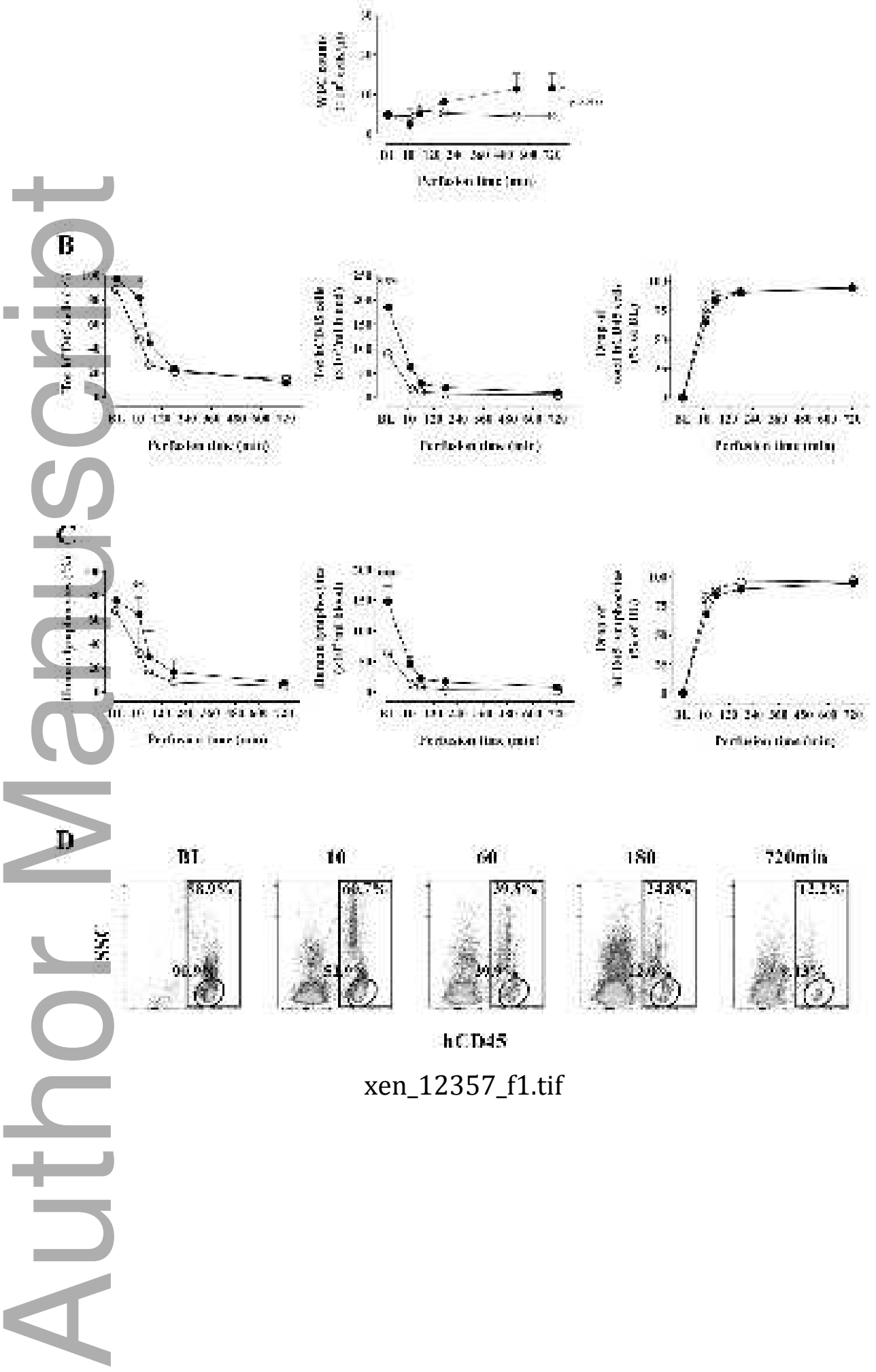

This article is protected by copyright. All rights reserved 


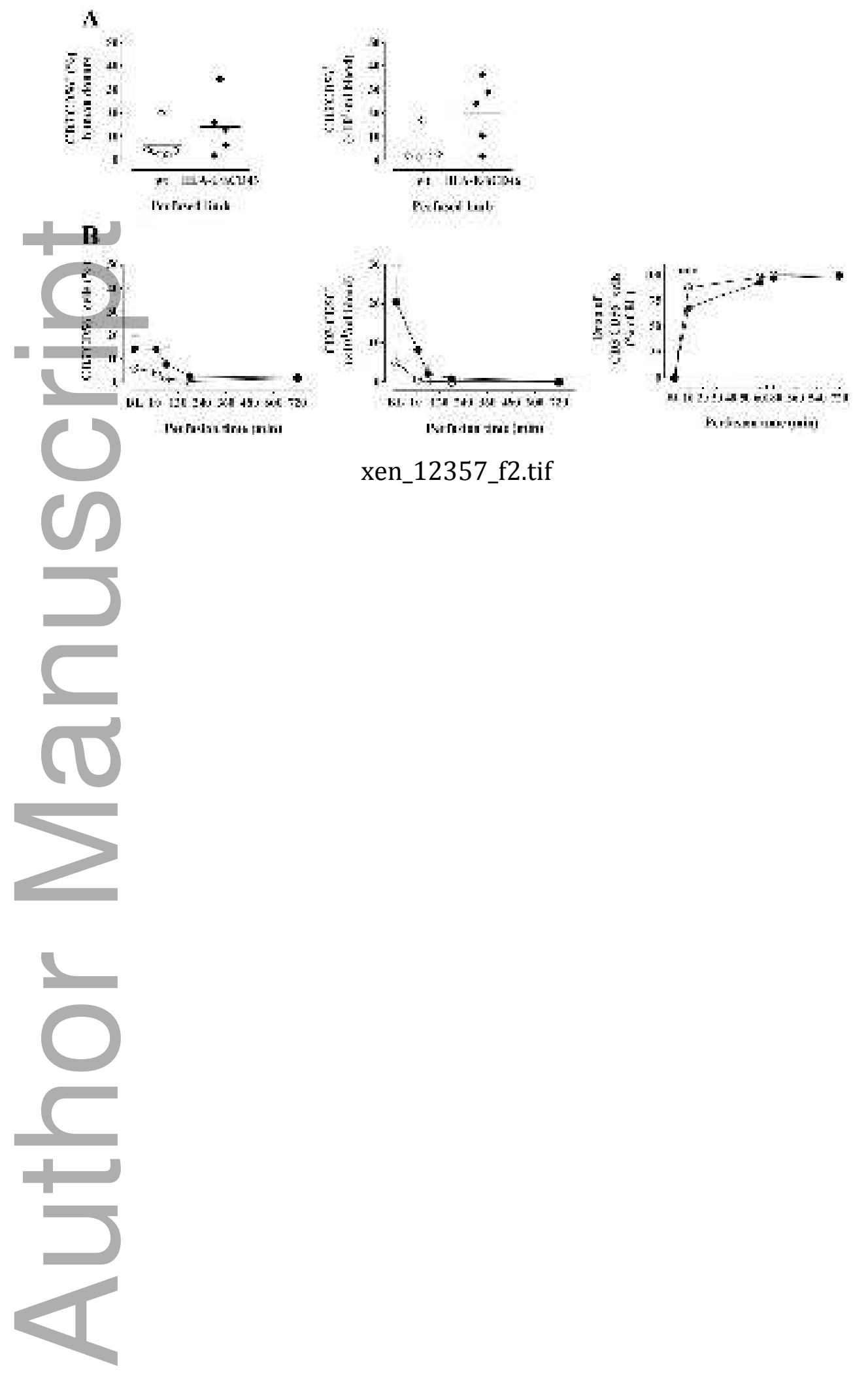

This article is protected by copyright. All rights reserved 
$A$

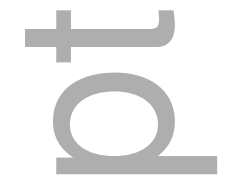

III A-

문
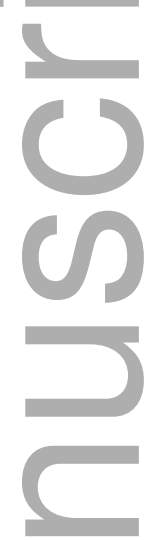

th.

$-20 \mathrm{~min}$

B

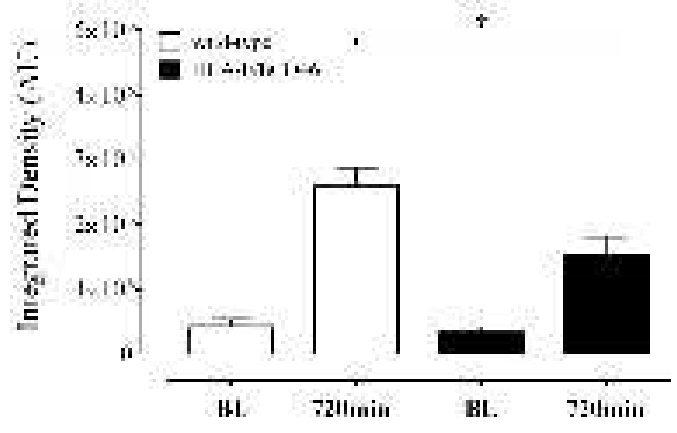

xen_12357_f3.tiff

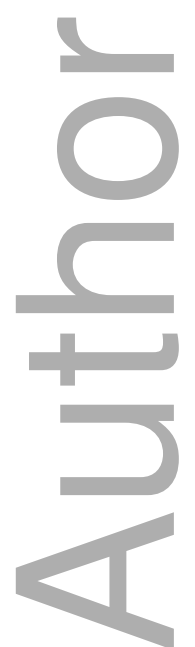


A

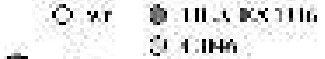

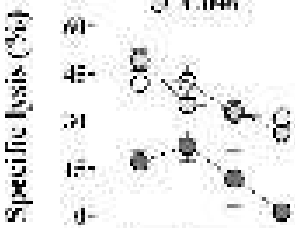

$$
\begin{aligned}
& \text { 4):1 } 20.1 \text { 19:1 5:1 } \\
& \text { F.:T rutia }
\end{aligned}
$$

B
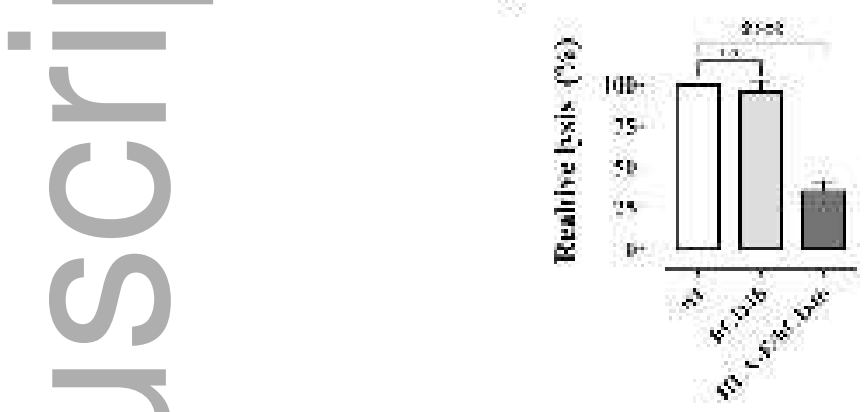

xen_12357_f4.tif
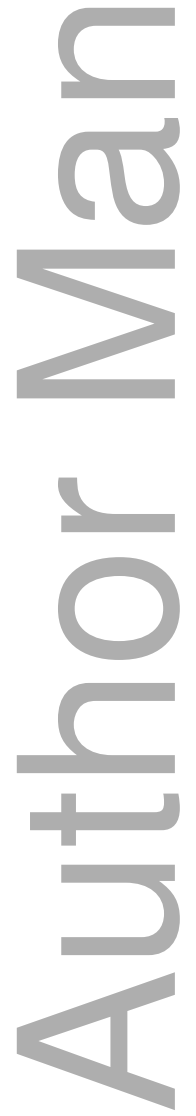


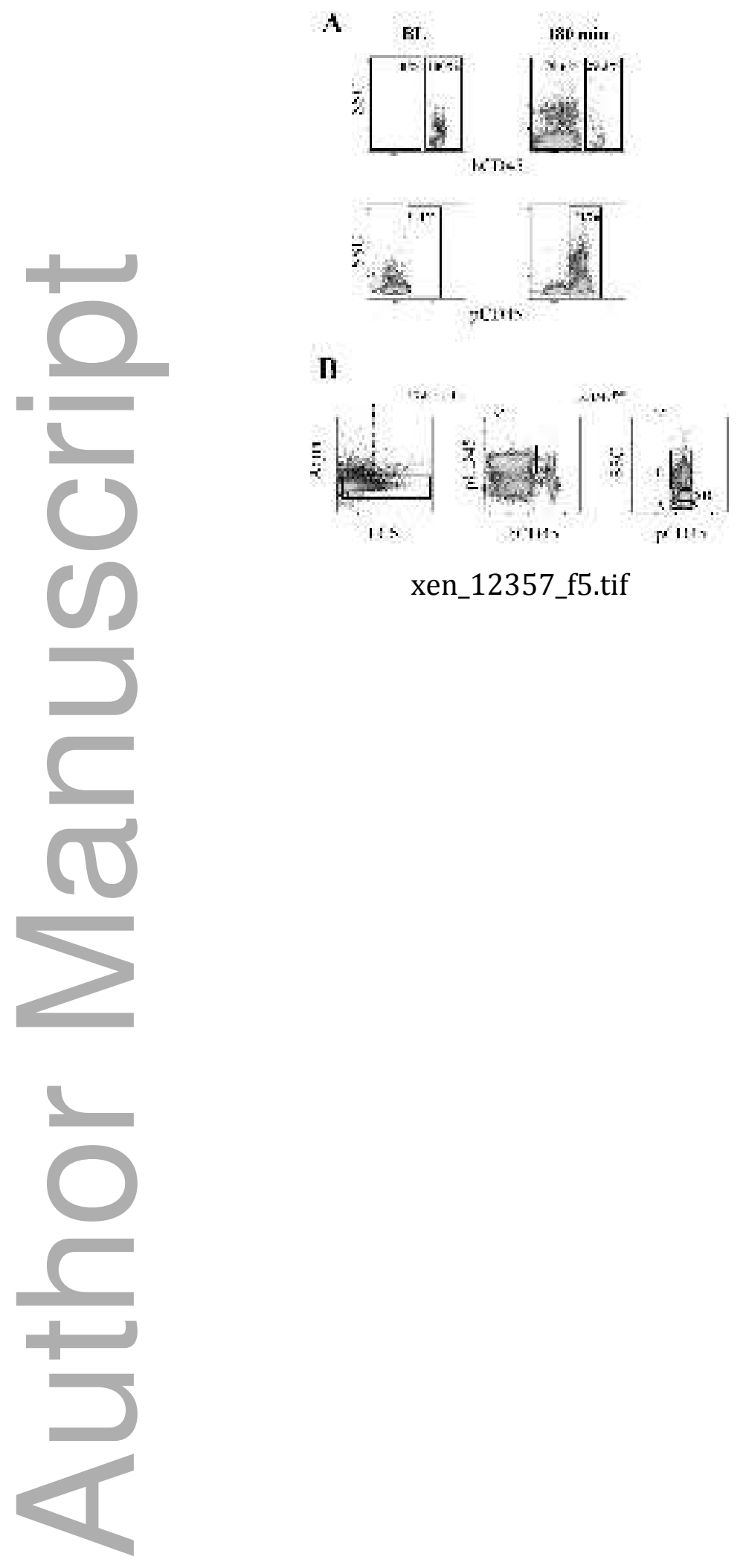

This article is protected by copyright. All rights reserved 


\section{University Library}

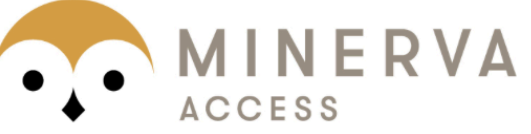

A gateway to Melbourne's research publications

Minerva Access is the Institutional Repository of The University of Melbourne

\section{Author/s:}

Puga Yung, G;Bongoni, AK;Pradier, A;Madelon, N;Papaserafeim, M;Sfriso, R;Ayares, DL;Wolf, E;Klymiuk, N;Bähr, A;Constantinescu, MA;Voegelin, E;Kiermeir, D;Jenni, H;Rieben, R;Seebach, JD

Title:

Release of pig leukocytes and reduced human NK cell recruitment during ex vivo perfusion of HLA-E/human CD46 double-transgenic pig limbs with human blood.

\section{Date:}

2018-01

\section{Citation:}

Puga Yung, G., Bongoni, A. K., Pradier, A., Madelon, N., Papaserafeim, M., Sfriso, R., Ayares, D. L., Wolf, E., Klymiuk, N., Bähr, A., Constantinescu, M. A., Voegelin, E., Kiermeir, D., Jenni, H., Rieben, R. \& Seebach, J. D. (2018). Release of pig leukocytes and reduced human NK cell recruitment during ex vivo perfusion of HLA-E/human CD46 doubletransgenic pig limbs with human blood.. Xenotransplantation, 25 (1), pp.e12357-e12357. https://doi.org/10.1111/xen.12357.

Persistent Link:

http://hdl.handle.net/11343/293759 